\title{
Characterization of Acidified Opal Shale and Dynamic Adsorption of Toluene
}

\author{
Mingyue Kou, Wei Zuo*, Xiangfu Li, Ruosong Hu, Pan Wang, Jixu Zhan
}

School of Environment, Harbin Institute of Technology, Harbin, China

\section{Email address:}

hit_koumingyue $a$ 126.com (Mingyue Kou), zuoweistar a 163.com (Zuo Wei)

${ }^{*}$ Corresponding author

\section{To cite this article:}

Mingyue Kou, Wei Zuo, Xiangfu Li, Ruosong Hu, Pan Wang, Jixu Zhan. Characterization of Acidified Opal Shale and Dynamic Adsorption of Toluene. Journal of Energy and Natural Resources. Vol. 7, No. 1, 2018, pp. 40-46. doi: 10.11648/j.jenr.20180701.16

Received: April 17, 2018; Accepted: May 4, 2018; Published: June 20, 2018

\begin{abstract}
Different kinds of acidified opal shale powders were obtained through the activation of natural opal shale powders with different concentrations of sulfuric acid. The natural opal shale and different acidified opal shale materials were characterized by X-ray diffraction, Fourier transform infrared spectroscopy, and scanning electron microscopy. It was found that the opal shale has good acid resistance stability. When the sulfuric acid concentration reaches a high concentration of 6 $\mathrm{mol} / \mathrm{L}$ in the acidification treatment, the opal shale can still maintain its original main silica structure. Natural opal shale is a typical mesoporous material with a BET specific surface area of about $12 \mathrm{~nm}$, but it also contains a small amount of micropores and macropores. Appropriate acid treatment can increase the specific surface area. An excessively high concentration of acid that exceeds $6 \mathrm{~mol} / \mathrm{L}$ sulfuric acid can destroy the main structure of the cation, resulting in a decrease in the specific surface area. In this paper, the adsorptive breakthrough curves for toluene, dynamic saturated adsorption capacity and other gas adsorption performances of these materials were studied. Finally, the best adsorption material was the $2 \mathrm{~mol} / \mathrm{L}$ sulfuric acid acidified opal shale at 333K under stirring for 4 hours.
\end{abstract}

Keywords: Opal Shale, Acid Activation, Adsorption of Toluene

\section{Introduction}

In China, Volatile Organic Compounds (VOCs) refer to organic compounds having a saturated vapor pressure of more than $70 \mathrm{~Pa}$ at normal temperature and a boiling point of $533 \mathrm{~K}$ or less at normal pressure, or volatile organic compounds having a vapor pressure of $10 \mathrm{~Pa}$ or more at $293 \mathrm{~K}$. Toluene is currently one of the most studied Volatile Organic Compounds (VOCs). Toluene produced in human-generated life is mainly derived from chemical plant products, fuel evaporation, and volatile solvent in pharmaceutical factories [1]. Toluene has toxicity and irritation. Excessive concentrations of toluene may even have risks of cancer. Therefore, research on the control method of toluene has always been one of the research hot topics in the field of environmental protection. Toluene pollution control methods mainly include destructive methods and recovery methods. The destructive methods include oxidation method and biological method. The recovery methods include absorption method, adsorption method, concentration method, and membrane separation method. The adsorption method has the advantages of simple operation and process, no secondary pollution, and recyclable adsorbent [2].

Opal shale is a rare clay mineral. The kind of lightweight shale in Heilongjiang Province used in this experiment is mainly composed of cristobalite, phosphorite and quartz. It is characterized by light brittleness, low hardness, small specific gravity, and strong water absorption. Most opal shales are gray in color, and they also show different colors due to the adsorption of different impurity molecules or ions [3]. As shown in Table 1, opal shale belongs to the amorphous structure of high-silicon and low-aluminum, mainly composed of $\mathrm{SiO}_{2}$ and $\mathrm{Al}_{2} \mathrm{O}_{3}$, and also contains a very small amount of $\mathrm{Fe}_{2} \mathrm{O}_{3}, \mathrm{CaO}, \mathrm{K}_{2} \mathrm{O}$ and other components. Opal shale has micropores and mesoporous structures, and has the characteristics of high porosity, large specific surface area, and strong adsorption performance [4]. Li [5] discussed the application of opal shale in the synthesis of polymer materials. The polymer/opal composites synthesized had a 
significant toughening effect on ABS resin. Wang [6] proposed that the opal shale has a good pore structure and permeability, so it can be used as a filter aid. This discovery provides a new source of raw materials for the filter aid industry. Yang [7] tested the adsorption properties of opal shale on Rhodamine B solution. The experiments showed that the opal shale has strong adsorption capacity for dyes. Opal shale has a great effect on decolorization. Chen [8] tested that the acid-modified opal shale has good decolorization ability to sugar liquor. You [9] use opal shale as raw material to prepare a new type of oil decoloring agent, and the decolorizing power of soybean oil reaches about 180 or so. Fan [10] uses opal shale as a carrier and tetrabutyl titanate as a titanium source. $\mathrm{A} \mathrm{TiO}_{2}$ /opal shale photocatalytic composite material was prepared by sol-gel method. Acid-treated opal shale facilitates increasing the thermal stability of its loaded $\mathrm{TiO}_{2}$. In addition, opal shale can also be used to adsorb toxic and harmful gas molecules, impurity elements in water, and pollutants in soil in the field of environmental governance [11-13].

The main components of the opal shale used in this article and the content of each component are shown in Table 1. Opal shale's porosity, specific surface area and hydrophobicity can be enhanced, and its adsorption performance to volatile organic compounds can be improved, by appropriate activation treatment. In this paper, opal shale was activated and modified by acidification of sulfuric acid. The optimum sulfuric acid activation conditions were determined by material characterization and the determination of the adsorption performance of toluene, which will be used for the future research of mesoporous mesoporous materials.

Table 1. Main components of natural opal shale.

\begin{tabular}{ll}
\hline Composition & Atomic Percentage Content (\%) \\
\hline $\mathrm{SiO}_{2}$ & 91.16 \\
$\mathrm{Al}_{2} \mathrm{O}_{3}$ & 3.56 \\
$\mathrm{Fe}_{2} \mathrm{O}_{3}$ & 0.43 \\
$\mathrm{~K}_{2} \mathrm{O}$ & 0.43 \\
$\mathrm{CaO}$ & 0.28 \\
Others & 4.14 \\
\hline
\end{tabular}

\section{Experiments and Methods}

\subsection{Chemicals and Materials}

Experimental opal shale was purchased from Heilongjiang Province; Cetyltrimethyl ammonium bromide (CTAB, 99\%), concentrated sulfuric acid (AR), sodium hydroxide (AR), methanol (AR), and toluene (AR) were purchased from Sinopharm (China). High purity nitrogen $\left(\mathrm{N}_{2}, 99.99 \%\right)$ was supplied by Liming Industrial Gases.

\subsection{Preparation of Acidified Opal Materials}

The opal shale original soil was ground into powder and screened through a 800 mesh sieve. Take $20 \mathrm{~g}$ of powder and $200 \mathrm{~mL}$ of sulfuric acid solution with different concentrations ( $1 \mathrm{~mol} / \mathrm{L}, 2 \mathrm{~mol} / \mathrm{L}, 3 \mathrm{~mol} / \mathrm{L}, 4 \mathrm{~mol} / \mathrm{L}, 5 \mathrm{~mol} / \mathrm{L}, 6 \mathrm{~mol} / \mathrm{L}$ ) Separately and put them into a stirrer at $333 \mathrm{~K}$ under stirring for 4 hours. After completion of the reaction and centrifugation, the precipitate was washed to a $\mathrm{pH}$ between 6 and 7. Then the materials was dried in an oven at $373 \mathrm{~K}$ for 15 hours, ground to a powder and passed through a 100 mesh sieve. The prepared samples were respectively named as SO-1.0, SO-2.0, SO-3.0, SO-4.0, SO-5.0, and SO-6.0.

\subsection{Characterization of Samples}

X-ray Diffraction (XRD) measurements were performed using an X-ray diffractometer from Empyrean, Netherlands, with $\mathrm{u}-\mathrm{K}$ radiation, and the diffraction angle ranged from $3^{\circ}$ to $90^{\circ}$. Fourier Transform Infrared Spectroscopy (FT-IR) was detected using a Nicolet 8700 Fourier-transform infrared spectrometer from the United States. The wavelength range of the scan was $400-4000 \mathrm{~cm}-1$. Using $\mathrm{KBr}$ as a qualitative agent, the sample to be tested and the dried $\mathrm{KBr}$ powder are thoroughly ground in a mortar and pestle at a ratio of 1:130, and uniformly mixed and compressed. Specific surface area (BET) and pore volume were determined using a Micromeritics ASAP 2020 Type Surface Area Porosimeter. The material to be tested was degassed at $623 \mathrm{~K}$ for 4 hours before testing. The specific surface area was measured by BET method, and the pore size distribution was determined by BJH method. Scanning Electron Microscopy (SEM) was used with the Zeiss sigma 500.

\subsection{Dynamic Adsorption Experiments}

The experimental setup for the adsorption of VOCs on opal shale was shown in Figure 1. The method used in the experiment was dynamic air distribution [14]. The high-purity nitrogen bottle was used as the experimental carrier gas. The nitrogen gas released from the nitrogen bottle is divided into three channels. They are respectively fed into a gas mitigation bottle, a steam generator and a toluene generator. And the three lines are fully mixed in the gas mitigation bottle. By adjusting the gas quality rotameter, the toluene gas, nitrogen gas, and water vapor gas flow rate and flow rate are controlled to control the concentration of toluene gas. The mixed gas is passed to a glass adsorption column containing an adsorbent for sufficient adsorption. The final test gas was analyzed by gas chromatography. The gas chromatographic analysis conditions were a hydrogen flame ionization detector (FID), with the column temperature of $318 \mathrm{~K}$, a detector temperature of $673 \mathrm{~K}$, and an auxiliary temperature of $523 \mathrm{~K}$. 


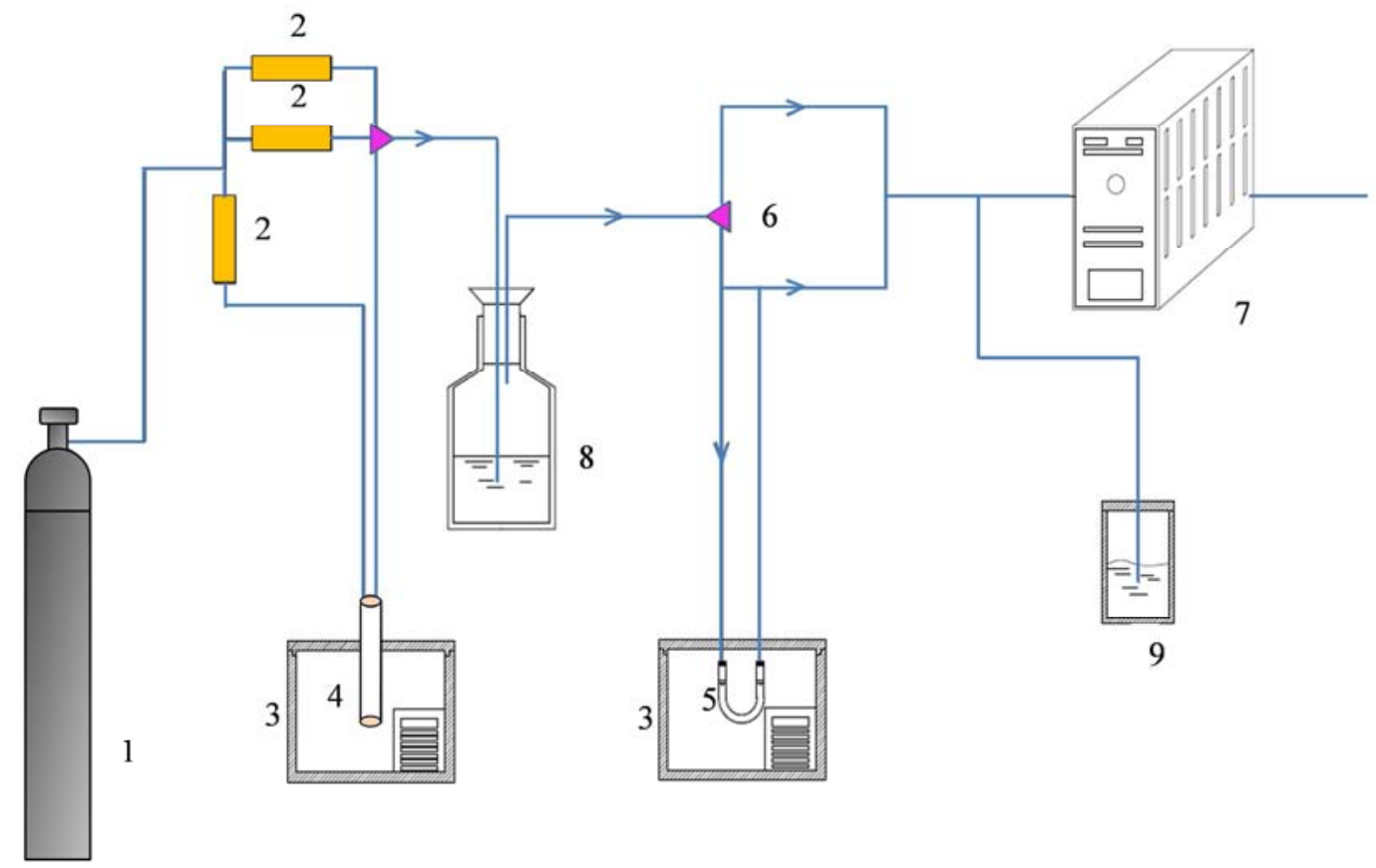

Figure 1. Dynamic adsorption experimental device.

1. Standard nitrogen cylinder; 2. Rotameter; 3. Constant temperature water bath; 4. Toluene generator; 5. Adsorption column; 6. Three-way valve; 7. Gas chromatograph; 8. Buffer bottle; 9. Tail gas absorption Apparatus

\section{Results and Discussion}

\subsection{Characterization of Materials}

\subsubsection{X-Ray Diffraction (XRD)}

Figure 2 shows XRD patterns of opal shale and sulfated acidified opal shale. By comparing the main peak position of XRD with the standard card, it can be seen that the main mineral components of natural opal shale are cristobalite and tridymite, as well as a small amount of clay minerals. There are two groups of strong peaks (101) and (200) of cristobalite. The disorder performance of cristobalite is very low, because it can be broken down relatively easily. The two strong peaks of tridymite are (200) and (0020). The treatment of opal shale with different concentrations of sulfuric acid did not affect its main structure. Only a small amount of clay mineral peaks fluctuate, and a small amount of small quartz peaks appeared. Comparing to the fact that the diffraction peaks of paeosite are almost completely destroyed when treated with $5 \mathrm{~mol} / \mathrm{L}$ acid, and its structure is completely destroyed [15], the opal shale can still maintain a good structural morphology when the concentration of sulfuric acid reaches a high concentration of $6 \mathrm{~mol} / \mathrm{L}$ in the acid treatment, indicating that the acid stability is high.

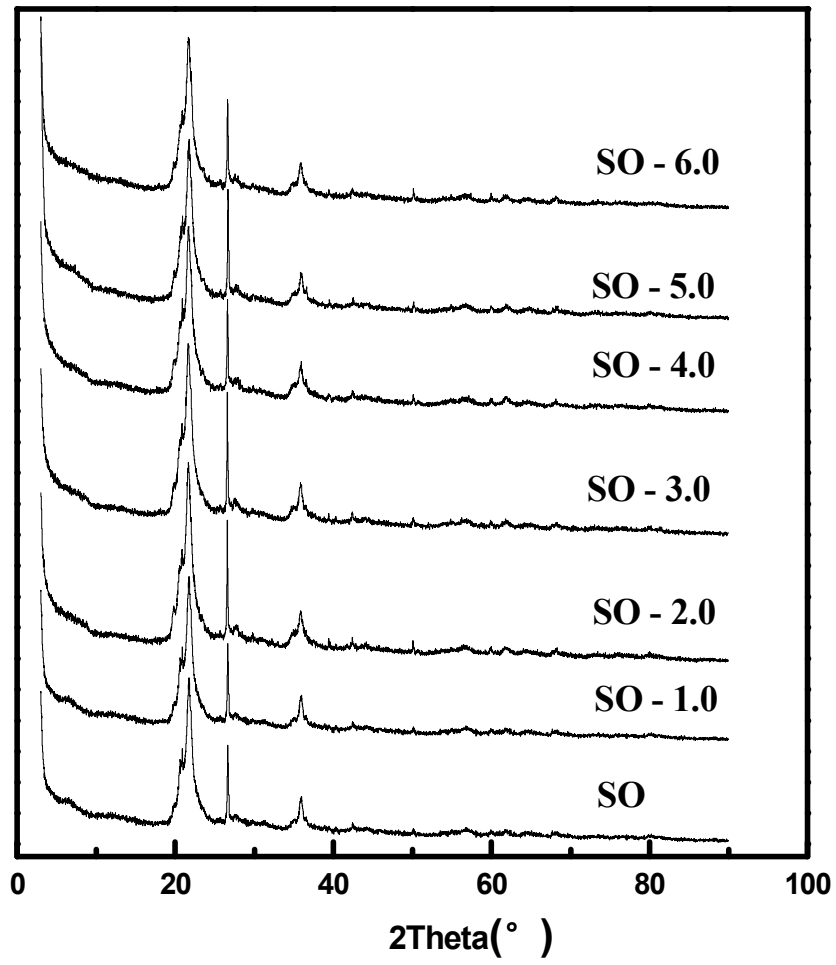

Figure 2. X-ray patterns of acidified opal shale. 


\subsubsection{Fourier Transform Infrared Spectroscopy (FT-IR)}

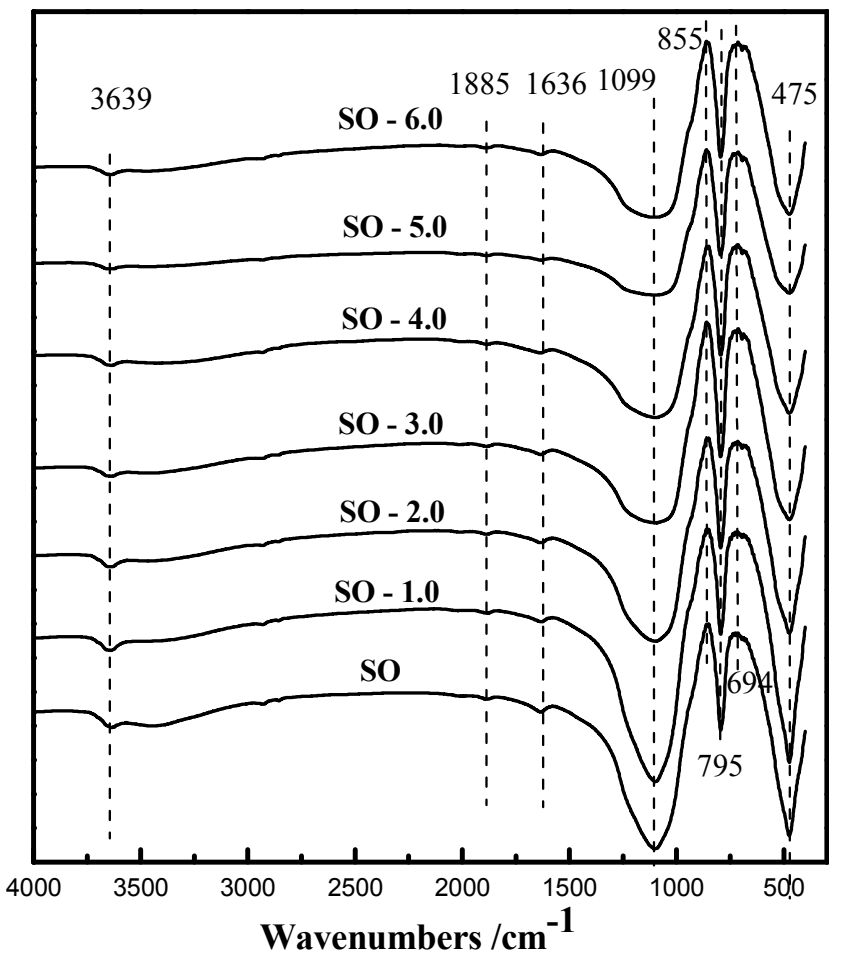

Figure 3. FT-IR of acidified opal shale.
Figure 3 shows FT-IR spectra of opal shale (SO) and six kinds of sulfated acidified opal shale (SO-1.0, SO-2.0, SO-3.0, SO-4.0, SO-5.0, SO-6.0). In the range of $3650 \mathrm{~cm}-1$ to $3200 \mathrm{~cm}-1$, the weak absorption water stretching vibration peak appeared at $3639 \mathrm{~cm}-1$. And this peak appeared to be weakened, with the increase of acid concentration. The bending vibration absorption peak of the hydroxy group at $1636 \mathrm{~cm}-1$ shows a weak peak after the acid treatment, indicating that the hydrophilicity of opal shale is weakened, which is more favorable improve its adsorption capacity of the organic gas mixed with water vapor [16].

\subsubsection{Scanning Electron Microscope (SEM)}

Figure $4 \mathrm{a}$ and $\mathrm{b}$ show the surface topography of natural opal shales. It can be seen that the irregular surface layer structure of the natural opal shale has more voids, and a small amount of opal spheroids can be seen occasionally. Figure 4 c and $\mathrm{d}$ are opal shales acidified with $2 \mathrm{~mol} / \mathrm{L}$ sulfuric acid. Most of the impurities in the material are removed due to the activation of sulfuric acid, causing the surface to appear a large number of strips and lamellar structures form nano-sized surfaces that are very rough. In addition, the opal shale itself has a large number of microporous structures, and the acidification treatment greatly increases the specific surface area, providing the possibility of improving the adsorption performance of organic gases such as toluene.
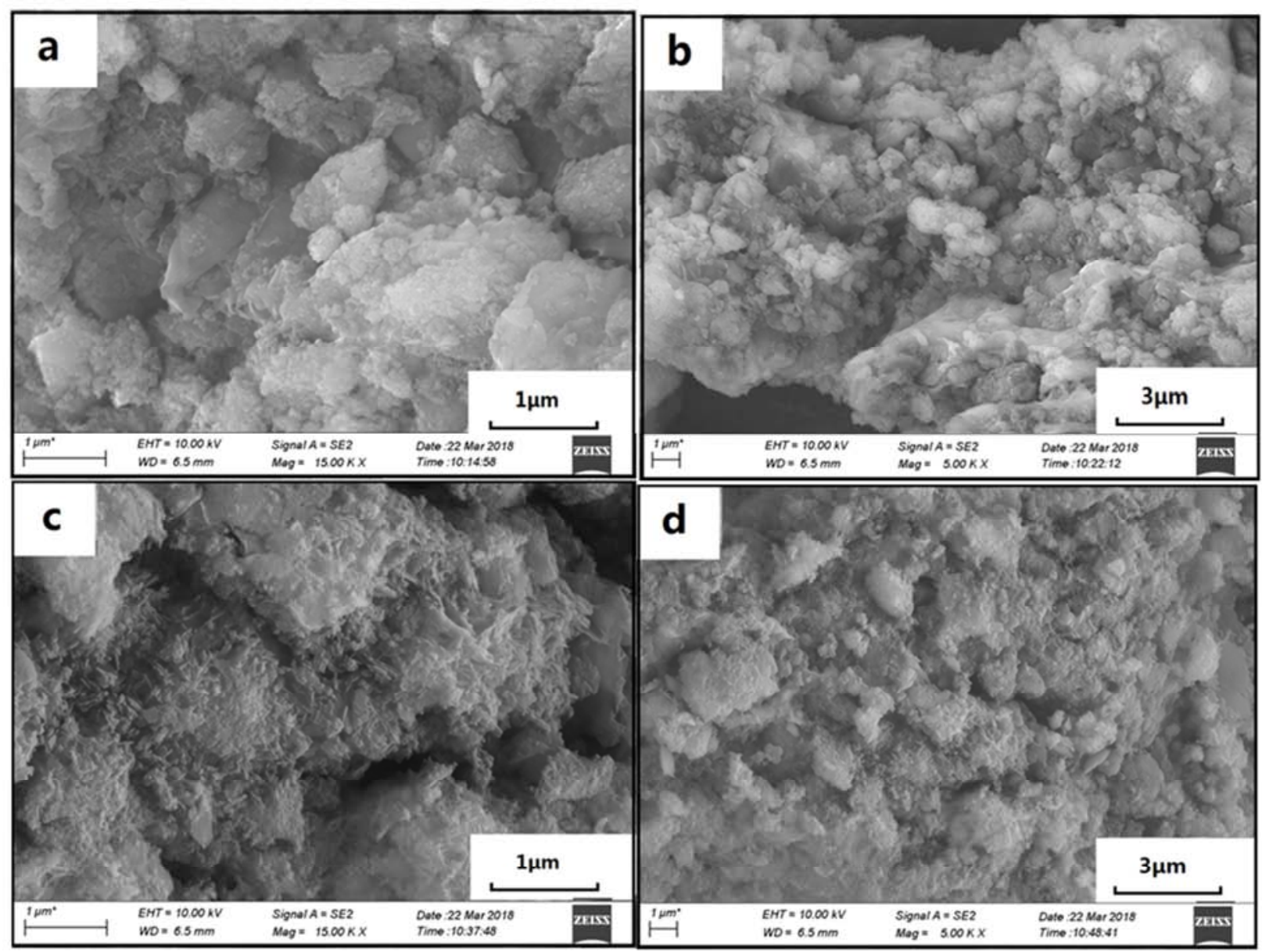

Figure 4. SEM of Opal shale and $2 \mathrm{~mol} / \mathrm{L}$ acidified opal shale. 


\subsection{Adsorption Properties of Acidified Opal Shale}

\subsubsection{Nitrogen Adsorption-Desorption Isotherms}
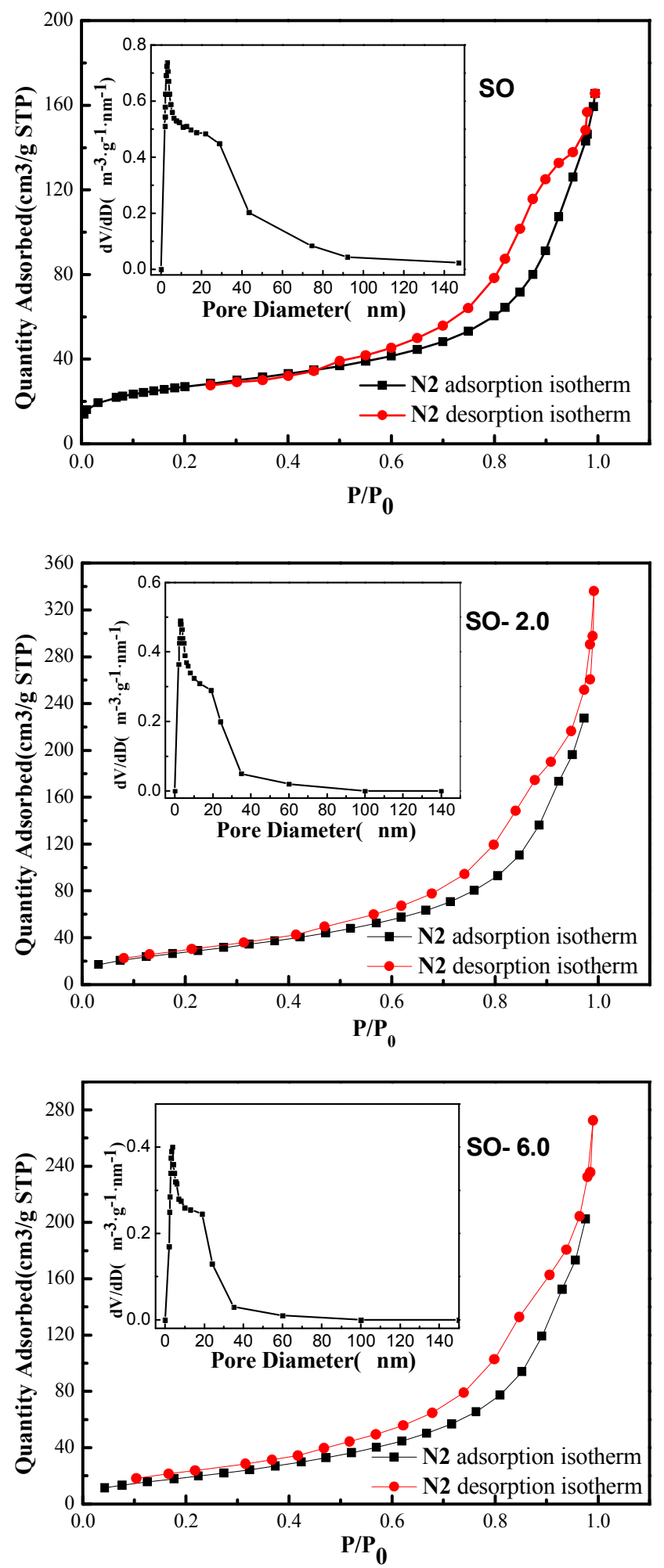

Figure 5. $\mathrm{N}_{2}$ adsorption-desorption curve of acidified opal shale.

Nitrogen adsorption-desorption isotherms and pore size distributions of opal shales are shown in Figure 5. The adsorption-desorption isotherm type of the opal shale is type
IV, and there are H3 hysteresis loops in all three materials. This shows that natural opal shale is a typical mesoporous material, but it also contains a small amount of micropores and macropores. The pore diameters are mostly distributed between $2 \mathrm{~nm}$ and $40 \mathrm{~nm}$, and the average BET pore size is $9.18 \mathrm{~nm}$. The pore size of the opal shale after acidification with $0.2 \mathrm{~mol} / \mathrm{L}$ and $0.6 \mathrm{~mol} / \mathrm{L}$ sulfuric acid was reduced, and they were mainly distributed between $2 \mathrm{~nm}$ to $30 \mathrm{~nm}$ and 2 $\mathrm{nm}$ to $20 \mathrm{~nm}$ respectively, with an average BET pore size of $14.69 \mathrm{~nm}$ and $14.20 \mathrm{~nm}$. There are two fundamental reasons for this, one being that the acid treatment makes the $\mathrm{SiO}_{2}$ in the clay mineral free amorphous [17]. The other reason is that the acid treatment diffuses the crystal structure in the clay, and the acid also dissolves the octahedron to open up more pores. When the sulfuric acid reaches a certain concentration, the cations in the octahedron are almost completely dissolved, and the $\mathrm{Si}-\mathrm{O}$ steric structure loses its support, causing the pores to collapse and the specific surface area to fall again [18-19]. Appropriate acid treatment can increase the specific surface area. But excessively high concentration of acid will destroy the octahedral structure and the hexagonal columnar structure of the cations.

\subsubsection{Dynamic Adsorption Penetration Characteristics}

Figure 6 shows the adsorption and breakthrough curves of toluene at different concentrations for the acidified shale and natural opal shale. Figure 7 shows the dynamic saturated adsorption capacity of acidified opal shale for toluene. The inlet flow rate of toluene was controlled at $0.3 \mathrm{~L} / \mathrm{min}$, and the toluene gas inlet gas concentration was $300 \mathrm{mg} / \mathrm{L}$. The reaction system was carried out at normal temperature and pressure, that is, the adsorption temperature was $293 \mathrm{~K}$ and the gas pressure was $1 \mathrm{~atm}$. The inlet concentration of toluene is controlled at $0.3 \mathrm{~L} / \mathrm{min}$. The penetration curve of the natural opal shale is the steepest, indicating that the adsorption rate is fast and the adsorption saturation is reached quickly. The porosity of the sulfuric acidified opal shale increased slightly, decreasing the mass transfer resistance during toluene adsorption and increasing the adsorption breakthrough time and the saturated adsorption capacity [20-22]. When the concentration of sulfuric acid is $2 \mathrm{~mol} / \mathrm{L}$, the breakthrough time and saturated adsorption capacity are the best. Compared with natural opal shale, the breakthrough time is increased by $177.78 \%$ and the saturated adsorption capacity is increased by $73.50 \%$. However, the sulfuric acid concentration is not as good as possible. When the sulfuric acid concentration is greater than $2 \mathrm{~mol} / \mathrm{L}$, the breakthrough time and saturated adsorption capacity of the acidified opal shale decrease as the acid concentration increases. From Table 2, it can be seen that the BET specific surface area and Langmuir specific surface area of the $6 \mathrm{~mol} / \mathrm{L}$ acidified opal shale are lower than that of the $2 \mathrm{~mol} / \mathrm{L}$ sulfated opal sulfate shale. The main reason is that excessive acid concentration destroys the pore structure of the opal shale surface, making large of micropores change to mesopores. In addition, the relative relationship between the diameter of the adsorbed 
gas molecules and the pore diameter of the adsorbent also has a great influence on the adsorption effect [23-24].

Table 2. Structural properties of $S O$, S O-2.0, and $S O-6.0$.

\begin{tabular}{llll}
\hline Sample & SO & SO-2.0 & SO-6.0 \\
\hline BET Surface Area $\left(\mathrm{m}^{2} / \mathrm{g}\right)$ & 96.31 & 105.41 & 74.17 \\
Langmuir Surface Area $\left(\mathrm{m}^{2} / \mathrm{g}\right)$ & 133.13 & 171.30 & 116.36 \\
BJH pore volume $\left(\mathrm{cm}^{3} / \mathrm{g}\right)$ & 0.25 & 0.42 & 0.52 \\
BJH pore diameter $(\mathrm{nm})$ & 12.10 & 14.69 & 14.20 \\
\hline
\end{tabular}

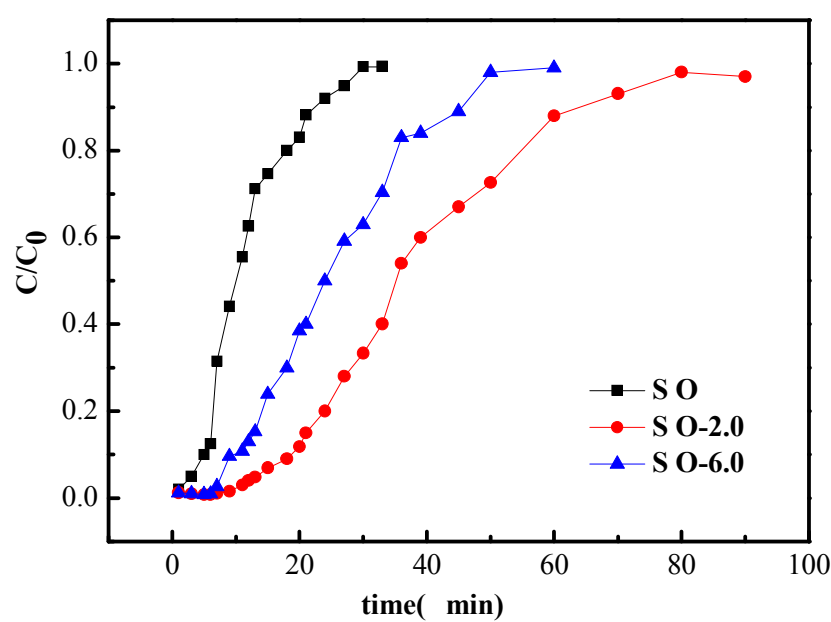

Figure 6. Dynamic Penetration Adsorption Curve of Toluene on Acidified Opal Shale.

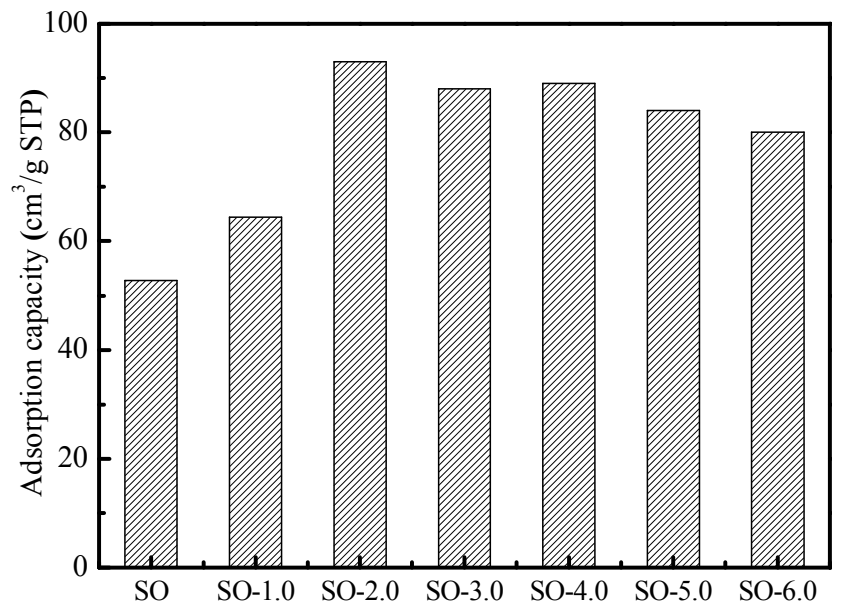

Figure 7. Dynamic saturated adsorption capacity of toluene on toluene in acidified opal shales.

\section{Conclusion}

Sulfuric acidification treatment enhances the structural order of opal shale. Opal shales have good acid stability. When the sulfuric acid concentration reaches a high concentration of $6 \mathrm{~mol} / \mathrm{L}$ in the acidification treatment, the opal shale can still maintain its original main silica structure. Acidification can remove most of the impurities in the material, giving it a large number of elongated and lamellar structures on the surface, increasing its specific surface area. Natural opal shale is a typical mesoporous material, but it also contains a small amount of micropores and macropores.
Appropriate acid treatment can increase the specific surface area. Excessively high concentration of acid will destroy the main structure of the cation, resulting in a decrease in the specific surface area. When the concentration of sulfuric acid is $2 \mathrm{~mol} / \mathrm{L}$, the adsorption time and saturated adsorption capacity of acidified opal shale are the best. Compared with natural opal shale, the breakthrough time is increased by $177.78 \%$ and the saturated adsorption capacity is increased by $130 \%$.

As a kind of clay mineral with good properties, opal shale will have very broad application prospects in adsorption and catalysis by changing its physical and chemical properties. It is also possible to consider using opal shale as a good catalyst carrier to carry metal ions, metal oxides and other particles on the surface thereof for further catalysis research. In China, it has found a large amount of opal shale in Yunnan, Liaoning, Inner Mongolia, Heilongjiang and other regions, but there are still few studies on its physicochemical properties. It is of great significance to deepen the study of the adsorption efficiency of opal shale, especially for the removal of pollutants such as exhaust gas, water and soil.

\section{Acknowledgements}

This work was financially supported by National Natural Science Fund Youth Fund (51708157), State Key Laboratory Open Fund for Urban Water Resources and Water Environment (QA201609-02), Harbin Applied Technology Research and Development Project (2017RAQXJ230).

\section{References}

[1] Li Liangbo, Chi Yong, Chen Yu, et al. Experimental study on dynamic adsorption of toluene on activated carbon fibers and the adsorbent regeneration $[\mathrm{J}]$. Environmental Pollution and Control, 2011, 33 (9): 70-74.

[2] Zheng Yuying, Dou Zhengjie, Du Han, et al. Recovery and Deep Purification of Industrial Organic Waste Gas [J]. Modern Chemical Industry, 2016 (12): 118-120.

[3] Ren Leifu. Discovery and study of shallow shale composed of shinyshishi stone [J]. Silicate Bulletin, 1982 (2): 15-19. K.

[4] Chai Erya, Pan Junan, Yuan Guolong and others. Preparation and Electrochemical Property of Polyaniline Coated Opal Shale/Sulfur Composite [J]. Journal of Inorganic Materials, 2017, 32 (11): 1165-1170.

[5] Li Qingshan, Chen Jie, Gao Jie, et al. Nenjiang Opal Light Shale and Its Application in Polymer Materials [J]. Nonferrous Metals Industry Industry Guide, 2003 (5): 21-23.

[6] Wang Zemin, Qiao Huanzeng. Study on Production of Filter Aid Using Lightweight Shale in Nenjiang River [J]. Silicate Bulletin, 1991 (6): 39-43.

[7] Yang Dianfan, Wei Cundi, Ning Weikun, et al. Structure and adsorption properties of Nenjiang opal shale [J]. Journal of Jilin University (Earth Science Edition), 2010, 40 (5): 1061-1065. 
[8] Chen Fuming, You Hong. Discussion On The Decoloring Ability Of Light Scheme By Adsorbent [J]. Non-metallic Mining, 1994 (5): 38-40.

[9] You Hong, Shen Jin. Lightweight shale adsorbents and their application in the decolorization of soybean oil [J]. Journal of Harbin Institute of Technology, 1994 (4): 71-74.

[10] Fan Xuemin, Bai Chenhua, Li Guanghui, er al. Effect of Surface Treatment of Opal Shale on Structure and Properties of Supported $\mathrm{TiO}_{2}[\mathrm{~J}]$. Multipurpose Utilization of Mineral Resources, 2018, 1 (2): 144-149.

[11] Gu Xiaohua, Shen Hong, Li Qingshan, et al. Progress in the development and application of opal light shale [J]. Chemical Journal, 2005, 19 (4): 36-41.

[12] Li Qingshan, Gu Xiaohua, Huang Xiang'an, et al. Research on discovery, creation and application of natural nanomaterials [C] Symposium on Functional Textiles and Nanotechnology Applications. 2003.

[13] Chai Erya, Pan Junan, Yuan Guolong, et al. Preparation and Electrochemical Performance of Polyaniline Coated Opal Shale/Sulfur Composites [J]. Journal of Inorganic Materials, 2017, 32 (11): 1165-1170.

[14] Wang Zemin, Wu Jijun, Ma Xiaofan, et al. Study on the production of filter aids using Nenjiang light shale [J]. Silicate Bulletin, 1991 (6): 39-43.

[15] Zhang Ling. Complete oxidation of formaldehyde at room temperature over zeolite supported Pt catalysts. [D]. Zhejiang University, 2017.

[16] Tang Hongming, Meng Yingfeng, Li Yingying, et al. Experimental study on the chemical behavior of kaolinite in acid [J]. Natural Gas Industry, 2006, 26 (10): 111-113.
[17] Stawiński W, Freitas O, Chmielarz L, et al. The influence of acid treatments over vermiculite based material as adsorbent for cationic textile dyestuffs [J]. Chemosphere, 2016, 153: 115-129.

[18] Suárez Barrios M, Gonzalez L V F, Rodriguez M A V, et al. 1995. Acid activation of a palygorskite with $\mathrm{HCl}$ : development of physico-chemical, textural and surface properties [J]. Applied Clay Science, 1995, 10 (3): 247-258.

[19] Tian G, Wang W, Li Z, et al. A functionalized hybrid silicate adsorbent derived from naturally abundant low-grade palygorskite clay for highly efficient removal of hazardous antibiotics [J]. Chemical Engineering Journal, 2016, 293: 376-385.

[20] Huang Haifeng, Ruan Wenjuan, Chen Hongyu, et al. Adsorption performance of ketone organic waste on Y zeolite [J]. Journal of Zhejiang University of Technology, 2014, 42 (5): 513-518.

[21] Chica A, Strohmaier K G, Iglesia E. Effects of zeolite structure and aluminum content on thiophene adsorption, desorption, and surface reactions [J]. Applied Catalysis B Environmental, 2005, 60 (3-4): 223-232.

[22] Jiang T, Zhong W, Jafari T, et al. Siloxane D4 adsorption by mesoporous aluminosilicates [J]. Chemical Engineering Journal, 2016, 289: 356-364.

[23] Huang Haifeng, Yu Xiang, Lu Yifeng, et al. Dynamic adsorption of VOCs by two mesoporous molecular sieves [J]. Chinese Journal of Environmental Science, 2010, 30 (4): 442-447.

[24] Li Ziyi. Experimental study and molecular simulation of adsorption of gas phase polycyclic aromatic hydrocarbons by mesoporous materials [D]. Beijing University of Science and Technology, 2017. 